\title{
Análise estrutural de folhas de Eugenia uniflora L. (Myrtaceae) coletadas em ambientes rural e urbano, SP, Brasil
}

\author{
Edenise Segala Alves ${ }^{1,2}$, Fernanda Tresmondi ${ }^{1}$ e Eduardo Luiz Longui ${ }^{1}$
}

Recebido em 12/02/2007. Aceito em 31/05/2007

\begin{abstract}
RESUMO - (Análise estrutural de folhas de Eugenia uniflora L. (Myrtaceae) coletadas em ambientes rural e urbano, SP, Brasil). Objetivou-se com este estudo verificar se plantas de Eugenia uniflora que crescem na cidade de São Paulo, diferem quanto à estrutura foliar, de exemplares encontrados em área rural, isenta de poluentes aéreos urbanos. Foram avaliadas, comparativamente, as dimensões da folha e, em microscopia de luz, a espessura dos tecidos foliares, a densidade de estômatos e de cristais da espécie, coletada em área rural e em dois pontos da cidade de São Paulo: canteiro central da Avenida dos Bandeirantes, com tráfego veicular intenso, portanto com alta carga de poluentes primários, e no Parque Estadual das Fontes do Ipiranga (PEFI) submetido a altas concentrações de poluentes secundários. Buscaram-se variações que possam ser decorrentes da poluição urbana. As folhas coletadas no meio urbano mostraram menores dimensões, menor espessura do mesofilo, maior densidade estomática e maior quantidade de cristais. A espessura do parênquima lacunoso sofreu redução, quando se comparam as plantas do ambiente rural e urbano; observou-se a menor espessura nas folhas submetidas a poluentes secundários. Não foram observadas variações qualitativas entre as folhas dos três locais avaliados. Considerando que folhas coletadas no meio urbano variaram menos entre si, quando comparadas àquelas de área rural, acredita-se que a poluição aérea da cidade possa ser responsável, pelo menos em parte, pelas variações observadas. Exposições padronizadas, em ambiente monitorado, devem ser realizadas para comprovar tal hipótese.
\end{abstract}

Palavras-chave: anatomia foliar, Eugenia uniflora, poluição aérea, ambiente urbano, pitanga

\begin{abstract}
Leaf anatomy of Eugenia uniflora L. (Myrtaceae) in urban and rural environments, São Paulo State, Brazil). The aim of this study was to compare leaves of Eugenia uniflora from the city of São Paulo with leaves of plants from a rural site. Leaf size, tissue thickness, and stomatal and crystal density of E. uniflora growing at two sites in the city of São Paulo were investigated by light microscopy and compared with samples from a rural area. The level and types of air pollutants varied at the urban sites. Primary pollutants were present on Bandeirantes Avenue and secondary ones in the park (Parque Estadual das Fontes do Ipiranga - PEFI). Urban leaves were smaller, thinner and with higher stomatal and crystal density. We observed greater spongy parenchyma thickness in leaves from the avenue when compared to those from the park. No qualitative differences were observed between urban and rural leaves. Leaves from the two urban sites showed similarities, but were different from rural leaves, so we believe that the differences observed may be attributed to the polluted environment of São Paulo. In order to confirm this hypothesis, control experiments should be done.
\end{abstract}

Key words: leaf anatomy, Eugenia uniflora, air pollution, urban environment, "pitanga"

\section{Introdução}

As plantas que vivem no meio urbano, numa grande metrópole como São Paulo, sofrem os efeitos da poluição do ar oriunda, principalmente, da grande frota automotiva, que produz uma carga elevada de poluentes gasosos e particulados (CETESB 2004). A observação de troncos de árvores que vivem em locais com tráfego intenso, revela a presença de uma camada escura de material particulado, que também se deposita nas folhas. Além dos particulados, estão presentes no ar urbano, elevadas concentrações de gases como dióxido de enxofre $\left(\mathrm{SO}_{2}\right)$, óxidos de nitrogênio $\left(\mathrm{NO}_{\mathrm{x}}\right)$, monóxido de carbono ( $\mathrm{CO}$ ), que são emitidos diretamente de fontes poluidoras e são classificados como poluentes primários (Freedman 1995). Existem também os fotoxidantes, como o ozônio $\left(\mathrm{O}_{3}\right)$ e o nitrato de peroxiacetila (PAN), que são os poluentes secundários produzidos por meio de reações fotoquímicas, a partir de alguns poluentes primários (Freedman 1995). Tais substâncias podem provocar alterações fisiológicas, bioquímicas e estruturais nas plantas, uma vez que são muito reativas e atacam as membranas celulares (Becana et al. 2000).

Várias espécies vegetais têm sido utilizadas como bioindicadoras da qualidade do ar, sendo que a maior

\footnotetext{
Instituto de Botânica, C. Postal 3005, 01061-970, São Paulo, SP, Brasil

2 Autor para correspondência: ealves@ibot.sp.gov.br
} 
parte é bioindicadora de resposta, ou seja, mostra sintomas visíveis. Dentre elas podem ser consideradas as plantas já presentes no local de estudo, denominadas de organismos passivos, ou plantas que são introduzidas de forma padronizada no ambiente a ser investigado, denominadas de organismos ativos (Falla et al. 2000).

Contudo, como a maioria dos trabalhos sobre biomonitoramento tem sido realizada por grupos europeus e norte-americanos, as espécies utilizadas são aquelas que vivem em climas temperados ou que têm interesse econômico. Comparativamente, nas regiões tropicais e subtropicais, os estudos sobre monitoramento biológico dos efeitos de poluentes aéreos com plantas são mais restritos e escassos (Klumpp et al. 2000).

No Brasil, já existem ou estão em andamento estudos que buscam espécies nativas ou adaptadas ao ambiente tropical com potencial para a bioindicação (Domingos et al. 1998; 2004). Dentre as mirtáceas, o gênero Psidium L. vem sendo avaliado (Moraes et al. 2002; 2004; Furlan et al. 2006; Pina \& Moraes 2007) e tem mostrado resultados promissores, o que incentiva a investigação de outros representantes desta família.

A família Myrtaceae compreende cerca de 130 gêneros e 4.000 espécies de plantas lenhosas, com distribuição predominantemente pantropical e subtropical, concentrada na região neotropical e na Austrália (Souza \& Lorenzi 2005). Suas espécies são arbustivas ou arbóreas, com folhas inteiras, de disposição alterna ou oposta e, às vezes, oposta cruzada, com estípulas muito pequenas (Joly 1977).

Segundo Metcalfe \& Chalk (1950) e Ferri (1971), as folhas de Myrtaceae são geralmente hipoestomáticas, com cutícula de espessura variável, podendo ser glabras ou apresentar tricomas em quantidade variável nas duas superfícies ou apenas em uma delas; os estômatos são em geral paracíticos, o parênquima clorofiliano distribui-se como paliçádico na superfície adaxial e lacunoso na abaxial, cavidades secretoras estão presentes em geral nas duas superfícies, idioblastos freqüentemente com cristais do tipo drusa também são comuns, o esclerênquima é o tecido mecânico predominante, e pode ou não estar associado ao sistema vascular. $\mathrm{O}$ autor descreve alguns aspectos da folha de E. uniflora, como epiderme glabra, estômatos do tipo paracítico apenas na epiderme abaxial, que correspondem ao padrão já mencionado para a família.

Costa et al. (1995), descreveram o sistema vascular de 11 espécies do gênero Eugenia L., incluindo E. uniflora. Segundo os autores, a espécie apresenta o padrão camptódromo-broquidródomo, no qual as nervuras secundárias se anastomosam desde a base, por meio de arcos, nas imediações da borda.

Enfocando o efeito da poluição na espécie, Silva et al. (2005) avaliaram os sintomas provocados por chuva ácida, em experimento controlado, e constataram necroses na folha com colapso dos tecidos foliares, hiperplasia de células parenquimáticas, além de muitos outros sintomas, o que mostra a sensibilidade da planta a contaminantes de origem antropogênica.

Levando em consideração que E. uniflora pode ser encontrada com facilidade na cidade de São Paulo, crescendo e frutificando em ambientes altamente contaminados por poluentes aéreos, realizou-se o presente estudo que objetivou comparar a estrutura anatômica da folha de indivíduos que crescem em ambientes submetidos à poluição aérea urbana com outros de área rural. Buscou-se detectar se a folha sofre modificações em seu padrão estrutural em decorrência da poluição urbana e, também, identificar quais são os melhores parâmetros morfométricos e ou anatômicos para se avaliar o efeito da poluição nas folhas dessa planta, contribuindo para a determinação do seu potencial bioindicador da poluição aérea.

\section{Material e métodos}

Foram coletados ramos de nove espécimes de Eugenia uniflora L. (Myrtaceae) - pitanga, sendo três deles procedentes de local submetido a intenso tráfego automotivo (canteiro central da Avenida dos Bandeirantes, próximo ao aeroporto de Congonhas e à estação Congonhas da CETESB, na cidade de São Paulo), local exposto a grande carga de material particulado e poluentes primários como $\mathrm{SO} 2, \mathrm{NOx}$ e CO (Tab. 1). Amostras de três indivíduos foram coletados em local não exposto ao tráfego automotivo, em área do Instituto de Botânica (IBt), localizado no Parque Estadual das Fontes do Ipiranga (PEFI). O PEFI, que abrange 526,38 ha, é um remanescente de Mata Atlântica encravado na região metropolitana de São Paulo (Fernandes et al. 2004). Embora o local de coleta não esteja exposto a uma carga direta de poluentes primários, é bastante afetado por poluentes secundários como o ozônio, que nos períodos de maior concentração desse gás, de agosto a dezembro, atinge valores elevados de até 100 ppb (Klumpp et al. 1994). Dados disponíveis para o mês de abril e junho, monitorados na área, mostram valores médios de 50,4 ppb (S.R. de Souza, comunicação pessoal). 
Tabela 1. Concentrações médias de poluentes primários presentes na Avenida dos Bandeirantes, São Paulo, SP, Brasil, monitorados pela Rede telemétrica da CETESB (Companhia de Tecnologia de Saneamento Ambiental). (Fonte: CETESB 2004).

\begin{tabular}{lc}
\hline Poluente & Ano de 2004 \\
\hline $\mathrm{NOx}(\mathrm{ppb})$ & 181 \\
$\mathrm{NO}_{2}\left(\mu \mathrm{g} \mathrm{m}^{3}\right)$ & 77 \\
$\mathrm{NO}\left(\mu \mathrm{g} \mathrm{m}^{3}\right)$ & 173 \\
$\mathrm{SO}_{2}\left(\mu \mathrm{g} \mathrm{m}^{3}\right)$ & 23 \\
$\mathrm{CO}(\mathrm{ppm})$ & 8,2 \\
Material Particulado $\left(\mu \mathrm{g} \mathrm{m}^{3}\right)$ & 48 \\
\hline
\end{tabular}

Como material de referência, foram coletadas folhas de três indivíduos em área rural, na cidade de Jarinu, distante cerca de $70 \mathrm{~km}$ de São Paulo que, devido às suas dimensões e localização, é isenta de poluentes urbanos.

$\mathrm{O}$ material coletado foi fixado em $\mathrm{FAA}_{70}$ permanecendo no fixador por 48 horas; em seguida foi armazenado em álcool a 70\%. No estudo, foram avaliadas folhas adultas do quarto nó, a partir do ápice do ramo, cujo tamanho foi padronizado. Fragmentos da região mediana da folha foram incluídos em polietilenoglicol 2000 (PEG) de acordo com Richter (1981), e seccionados em micrótomo rotativo (Olympus CUT 4055) com espessura de $18 \mu \mathrm{m}$.

As secções foram gotejadas com água destilada para a retirada do PEG, coradas com solução aquosa (9:1) de azul de astra e safranina (1\%), desidratadas em série etílica crescente, submetidas a acetato de $n$ butila e montadas em resina sintética (Permount) (Kraus \& Arduin 1997).

Para a análise da epiderme foram preparadas secções paradérmicas a partir de fragmentos da região mediana das duas folhas do quarto nó dos três espécimes, dos três locais, que foram clarificados utilizando-se hidróxido de sódio (10\%). O material permaneceu nessa solução por 48 horas em estufa a $40{ }^{\circ} \mathrm{C}$. Posteriormente, foi colocado em hipoclorito de sódio (20\%) por 24 horas, sendo então lavado com água destilada, corado com azul de astra e safranina aquosos (9:1) e montado em glicerina a 50\% (Kraus \& Arduin 1997).

A largura e o comprimento das folhas foram estabelecidos com régua milimetrada, sendo amostradas 80 folhas, dispostas entre o terceiro e o décimo nó, a partir do ápice, para cada espécime.

Nas secções transversais foram estabelecidas, com o auxílio de microscópio Zeiss equipado com medidor semi-automático (Retarmed), a espessura do mesofilo, do parênquima paliçádico e do lacunoso.

A densidade estomática foi determinada nas folhas diafanizadas, contando-se o número de estômatos presentes em $1 \mathrm{~mm}^{2}$, projetado em superfície plana, empregando-se microscópio Zeiss com sistema de projeção. Para a avaliação da quantidade de cristais em secção transversal utilizou-se uma área de mesma medida empregada na contagem dos estômatos, sendo que para todas as quantificações foram realizadas 20 repetições.

Para a determinação das diferenças entre os locais de amostragem, de cada variável quantitativa, aplicouse análise de variância paramétrica ou não paramétrica, quando não houve distribuição normal ou igualdade de variâncias. Quando o nível de significância $(\mathrm{p}<0,05)$ da análise foi atingido, aplicou-se um teste de comparações múltiplas, paramétrico (teste F) ou não paramétrico (Student-Newman-Keuls), para identificação das diferenças entre os tratamentos $(\mathrm{p}<0,05)$. Para a realização das análises empregou-se o programa estatístico SigmaStat.

\section{Resultados}

A folha de Eugenia uniflora é dorsiventral, glabra e hipoestomática, com estômatos do tipo paracítico (Fig. 1-2). Apresenta epiderme unisseriada e parênquima paliçádico disposto numa única camada conspícua e parênquima lacunoso formado por sete a nove camadas de células (Fig. 2); registra-se, tanto entre as células do parênquima paliçádico como lacunoso, a presença de idioblastos contendo drusas e cristais prismáticos possivelmente de oxalato de cálcio (Fig. 2). Glândulas podem ser observadas tanto na superfície adaxial como na abaxial (Fig. 10); o sistema vascular, na nervura central (Fig. 3-4), apresenta floema interxilemático; e é circundado por fibras provavelmente de origem pericíclica, que por sua vez são circundados por células com formato distinto das demais e que, pela posição e aspecto, correspondem à endoderme; ainda na nervura central, registra-se a presença de colênquima anelar (Fig. 4).

Alguns aspectos quantitativos da folha foram avaliados e são apresentados na Tab. 2. Quando são comparadas as dimensões médias das folhas dos indivíduos provenientes dos três locais de estudo, verifica-se que os indivíduos coletados em Jarinu apresentaram folhas com as maiores dimensões, enquanto aqueles coletados no IBt apresentaram as menores. Com relação aos tecidos foliares, não foram encontradas variações estatisticamente significativas 
Tabela 2. Características morfométricas e anatômicas de folhas de Eugenia uniflora L. coletadas em ambiente rural e urbano.

\begin{tabular}{lrrr}
\hline \multirow{2}{*}{ Características avaliadas } & \multicolumn{3}{c}{ Locais } \\
\cline { 2 - 4 } & \multicolumn{1}{c}{ Jarinu } & Bandeirantes & IBt \\
\hline Comprimento da folha $(\mathrm{cm})$ & $5,1 \pm 0,5^{\mathrm{a}}$ & $4,8 \pm 1,1^{\mathrm{b}}$ & $3,8 \pm 0,7^{\mathrm{c}}$ \\
Largura da folha $(\mathrm{cm})$ & $2,4 \pm 0,2^{\mathrm{a}}$ & $2,2 \pm 0,5^{\mathrm{b}}$ & $1,8 \pm 0,5^{\mathrm{c}}$ \\
Espessura do mesofilo $(\mu \mathrm{m})$ & $264,5 \pm 12,2^{\mathrm{a}}$ & $204,4 \pm 28,7^{\mathrm{b}}$ & $203,6 \pm 14,8^{\mathrm{b}}$ \\
Espessura do parênquima paliçádico $(\mu \mathrm{m})$ & $60,3 \pm 5,8^{\mathrm{a}}$ & $43,8 \pm 7,9^{\mathrm{c}}$ & $53,3 \pm 4,5^{\mathrm{b}}$ \\
Espessura do parênquima lacunoso $(\mu \mathrm{m})$ & $184,1 \pm 12,4^{\mathrm{a}}$ & $138,5 \pm 23,8^{\mathrm{b}}$ & $128,5 \pm 15,4^{\mathrm{b}}$ \\
Densidade estomática $\left(1 \mathrm{~mm}^{2}\right)$ & $59 \pm 13^{\mathrm{c}}$ & $98 \pm 14^{\mathrm{a}}$ & $67 \pm 8^{\mathrm{b}}$ \\
Densidade de cristais $\left(1 \mathrm{~mm}^{2}\right)$ & $0,37 \pm 0,9^{\mathrm{b}}$ & $5,7 \pm 3,5^{\mathrm{a}}$ & $5,18 \pm 3,3^{\mathrm{a}}$ \\
\hline
\end{tabular}

Valores indicam a média e o desvio padrão. Valores seguidos pelas mesmas letras, não diferem estatisticamente entre si a 5\% de probabilidade.
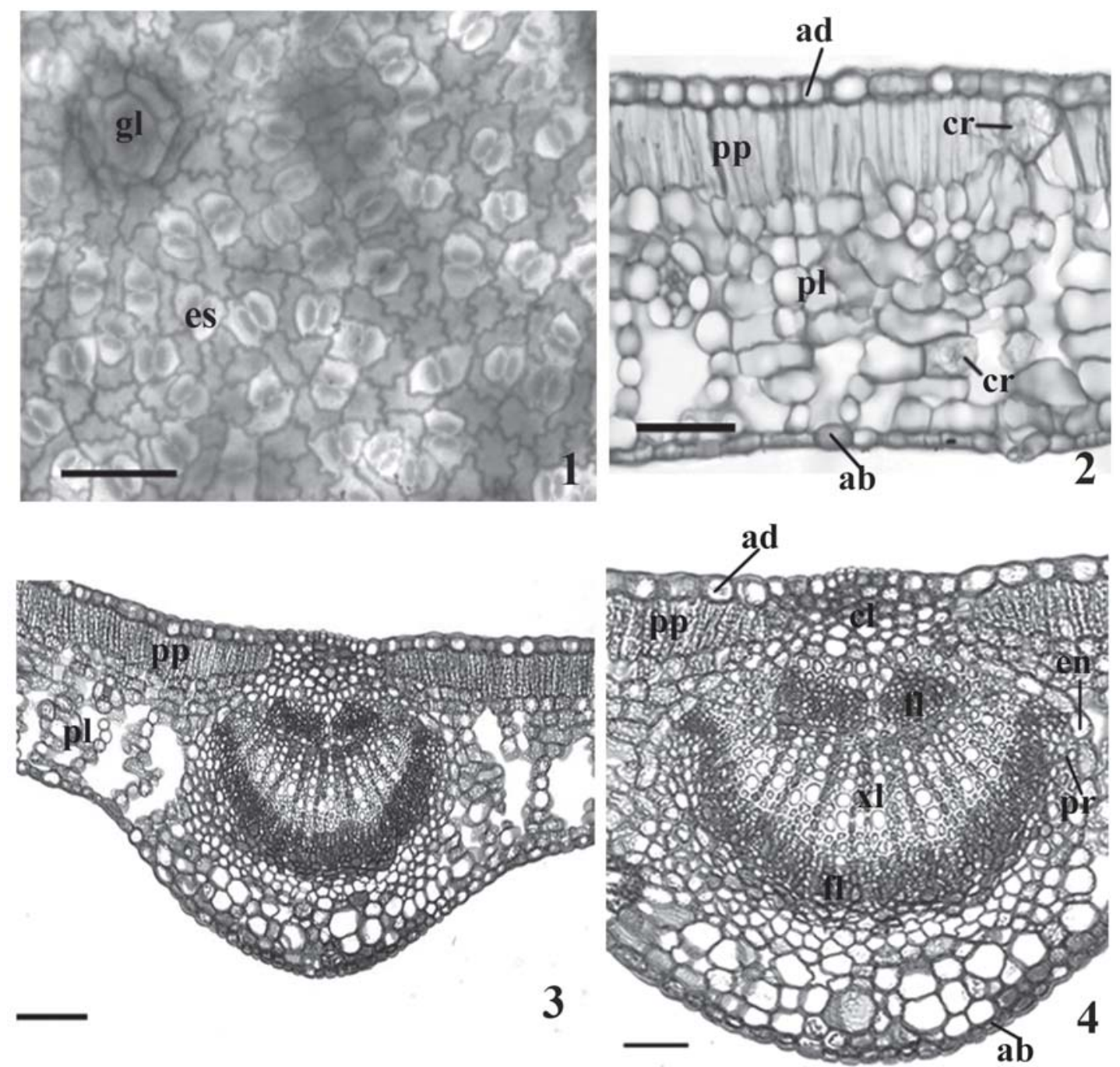

Figuras 1-4. Fotomicrografias de secções da folha de Eugenia uniflora L. coletada em área rural (Jarinu). 1. Secção paradérmica da superfície abaxial. 2. Secção transversal. $($ Barra $=50 \mu \mathrm{m})$. 3. Secção transversal da nervura principal $($ Barra $=100 \mu \mathrm{m})$. 4. Detalhe da nervura principal em secção transversal $($ Barra $=50 \mu \mathrm{m}) .(\mathrm{ab}=$ superfície abaxial; ad $=$ superfície adaxial; $\mathrm{cl}=\mathrm{colênquima;} \mathrm{cr}=\mathrm{cristal}$; en = endoderme; es = estômato; $\mathrm{fl}=$ floema; $\mathrm{gl}=$ glândula; $\mathrm{pl}=$ parênquima lacunoso; $\mathrm{pp}=$ parênquima paliçádico; $\mathrm{pr}=$ periciclo; $\mathrm{xl}=\mathrm{xilema})$. 
na espessura do mesofilo e na espessura das células do parênquima lacunoso entre os indivíduos coletados em São Paulo; tais valores foram menores que aqueles obtidos para os espécimes de Jarinu. A espessura do parênquima paliçádico variou entre os três locais, sendo
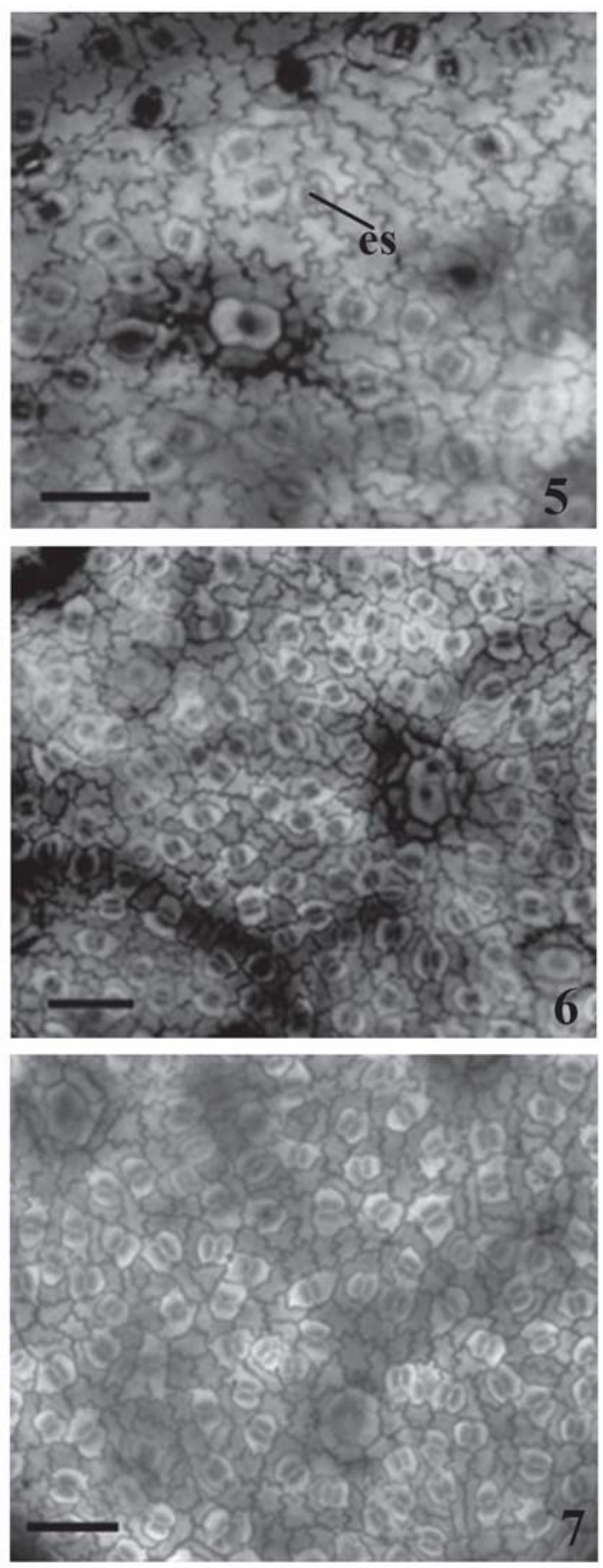

Figuras 5-7. Fotomicrografias de secções paradérmicas da folha de Eugenia uniflora L. que mostram a superfície epidérmica abaxial com estômatos do tipo paracítico. 5. Jarinu. 6. Av. dos Bandeirantes. 7. Instituto de Botânica (IBt). (Barra $=50 \mu \mathrm{m})$. (es = estômato). que os indivíduos procedentes do canteiro da Av. dos Bandeirantes apresentaram os menores valores médios e aqueles de Jarinu os maiores.

A densidade estomática variou nos espécimes dos três locais avaliados, sendo que os indivíduos da Av. dos Bandeirantes, comparativamente sujeitos à maior carga de poluentes aéreos, mostraram a maior densidade e os de Jarinu a menor (Tab. 2), (Fig. 5-7).

Em relação à quantidade de cristais e drusas, observou-se maior abundância nos espécimes oriundos de São Paulo, sendo que estes foram muito escassos nos indivíduos coletados em Jarinu (Tab. 2), (Fig. 8-10).

Qualitativamente, a estrutura foliar de E. uniflora não variou entre os indivíduos coletados nos diferentes ambientes. Contudo, quantitativamente, as folhas coletadas em Jarinu mostraram mesofilo mais espesso, em decorrência da maior espessura dos parênquimas paliçádico e lacunoso (Fig. 11-13).

\section{Discussão}

A estrutura foliar de Eugenia uniflora coletada em indivíduos adultos em ambiente rural e urbano não diferiu qualitativamente e está de acordo a descrição da mesma como se vê nos trabalhos de Bandulska (1930), Van Wyk et al. (1982), Machado et al. (1988) e Fontenelle et al. (1994).

Quantitativamente, as dimensões das folhas de E. uniflora variaram entre plantas coletadas no meio urbano e rural. Observou-se uma variação de tamanho nas folhas provenientes desses dois ambientes. Alterações nas dimensões das folhas em plantas submetidas à poluição aérea são mencionadas na literatura. Sharma \& Tyree (1973) compararam as dimensões de folhas de várias populações de Liquidambar styraciflua L. e verificaram a diminuição no comprimento das folhas de indivíduos crescendo em local próximo a usina termoelétrica movida a carvão, portanto, local com elevados índices de poluentes primários, especialmente de material particulado. Em experimento com Populus alba L., em sistema no qual apenas parte das folhas da planta foram fumigadas com ozônio, Fares et al. (2006) observaram diminuição no tamanho e alteração na forma de folhas expostas indiretamente ao gás e que surgiram uma semana após o início da exposição da planta.

Além de variações morfométricas, foi observada, nas folhas coletadas em São Paulo, menor espessura do mesofilo em comparação com as plantas de ambiente rural. Eleftheriou (1987) comparando folhas 
de oliveiras de ambiente rural e urbano, também encontrou redução nestas últimas e atribuiu tal fato a uma diminuição nos espaços aéreos do mesofilo, o que poderia, segundo o autor, ser uma estratégia adaptativa ao ambiente que apresenta grandes concentrações de gases tóxicos. Evans et al. (1996) também observaram redução na espessura foliar de Rudbeckia laciniata L., Rubus canadensis L. e Sassafras albidum (Nutt.) Nees submetidas ao ozônio e Bennet et al. (1992) verificaram uma diminuição na espessura da folha de algumas espécies sensíveis, quando comparadas a outras tolerantes à poluição atmosférica. Na cidade de São Paulo, Alves et al. (2001) constataram, em híbrido do gênero Tradescantia (clone 4430), uma diminuição na espessura da folha em plantas submetidas à altas concentrações de poluentes primários.

No ambiente urbano, a maior proporção de parênquima paliçádico foi observada nas folhas coletadas no IBt, local com altas concentrações de ozônio. Isto pode representar uma resposta que leva à redução dos espaços intercelulares, os quais facilitam a difusão do ozônio no interior da folha. O ozônio é, dentre os poluentes aéreos, o mais tóxico, uma vez que leva à formação de espécies ativas de oxigênio (EAO) nas células, que são muito reativas e danificam moléculas vitais como proteínas, lipídios e ácidos nucléicos, afetando as membranas celulares e alterando o metabolismo celular (Bray et al. 2000). Os resultados de Ferdinand et al. (2000) parecem confirmar essa hipótese. Os autores compararam dois genótipos de Prunus serotina Ehrh. e constataram que o genótipo tolerante ao ozônio (MO-7) apresentou, em relação ao sensível (R-12), maior proporção de parênquima paliçádico e menor de parênquima lacunoso. Os autores discutem que a tolerância do genótipo MO-7 deve-se ao fato de que a maior proporção de parênquima paliçádico leva à maior compactação do mesofilo, o que dificulta a difusão do ozônio no interior da folha. Fares et al. (2006) também observaram maior compactação do mesofilo em folhas de Populus alba expostas ao ozônio.

A densidade estomática variou nos espécimes dos três locais avaliados e os maiores valores foram encontrados nas folhas coletadas na Av. dos Bandeirantes, submetidas à altas concentrações de poluentes primários. $\mathrm{O}$ aumento na densidade estomática foi registrado por outros autores, em diferentes plantas submetidas a poluentes aéreos (Masuch et al. 1992; Päänkkönen et al. 1995; Päänkkönen et al. 1997) e déficit hídrico (Larcher 2000).
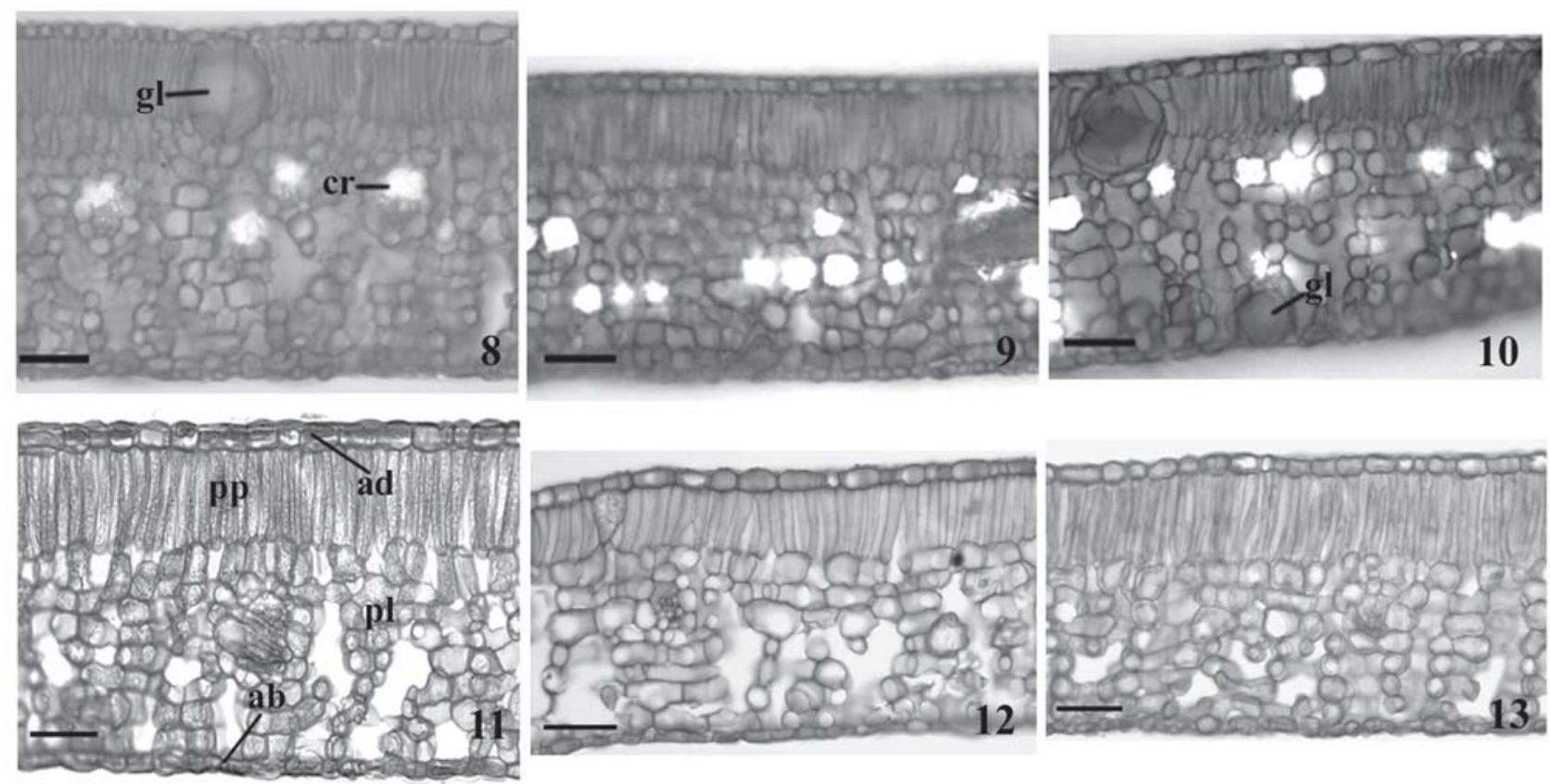

Figuras 8-13. Fotomicrografias de secções transversais da folha de Eugenia uniflora L. 8-10. Vista sob luz polarizada, destacando a presença de drusas no mesofilo. 8. Jarinu. 9. Av. dos Bandeirantes. 10. Instituto de Botânica (IBt). 11-13. Vista sob luz comum. 11. Jarinu. 12. Av. dos Bandeirantes. 13. Instituto de Botânica (IBt). (Barra $=50 \mu \mathrm{m})$. $(\mathrm{ab}=$ superfície abaxial; ad = superfície adaxial; $\mathrm{cr}=$ cristal; $\mathrm{gl}=$ glândula; $\mathrm{pl}$ = parênquima lacunoso; $\mathrm{pp}=$ parênquima paliçádico) . 
A análise comparativa das folhas de E. uniflora proveniente de ambiente rural e urbano mostrou diferenças consistentes na quantidade de cristais. Contudo, não se pode atribuir a maior abundância de cristais nos espécimes coletados em São Paulo apenas ao efeito da poluição, uma vez que a composição do solo é de fundamental importância no que se refere à formação de cristais nas plantas, porém a quase ausência de cristais nas folhas coletadas no ambiente rural evidencia alguma influência da poluição em relação à presença desses. Segundo Franceschi \& Horner (1980) a síntese de oxalatos está relacionada com o balanço iônico da planta, portanto os cristais, que na sua maioria são compostos de oxalato de cálcio, representam uma estratégia da planta para manter o equilíbrio iônico que é afetado quando a carga de poluentes é elevada. $\mathrm{O}$ aumento na quantidade de cristais é uma resposta que vem sendo observada em diferentes plantas submetidas a poluentes gasosos e chuva ácida (Adams et al. 1990; Fink 1991). Poluentes gasosos, como o ozônio, aumentam a permeabilidade das membranas celulares, promovendo um influxo de $\mathrm{Ca}^{++}$do apoplasto para o interior das células. Portanto, a formação de cristais seria uma reação de defesa para encapsular o excesso de cálcio no interior da célula (Fink 1991).

Embora tenham sido avaliadas apenas algumas características anatômicas da folha, e os indivíduos coletados estejam em diferentes condições de solo, características como a espessura do mesofilo, a espessura do parênquima lacunoso e a quantidade de cristais não variaram entre os indivíduos dos dois locais da cidade, porém diferiram daqueles coletados em ambiente rural. Tais resultados indicam que a poluição aérea presente na cidade possa ser, pelo menos em parte, a responsável pelas alterações encontradas, e que a planta responde de forma detectável aos efeitos da poluição. Experimentos mais controlados, envolvendo não apenas agentes passivos, mas também agentes ativos, sob condições de exposição controlada e solo padronizado, poderão esclarecer o potencial bioindicador de $E$. uniflora à poluentes aéreos urbanos.

\section{Agradecimentos}

Os autores agradecem à Dra. Marisa Domingos e à Dra. Sílvia Ribeiro de Souza, Seção de EcologiaIBt, pelas sugestões e dados relativos à concentração de ozônio no IBt; ao CNPq, pelas bolsas de Produtividade para E.S. Alves e Iniciação Científica para E.L. Longui.

\section{Referências bibliográficas}

Adams, C.M.; Caporn, S.J.M. \& Hutchinson, T.C. 1990. Crystal ocurrence and wax disruption on leaf surfaces of cabbage treated with simulated acid rain. New Phytologist 114: 147-158.

Alves, E.S.; Giusti, P.M.; Domingos, M.; Saldiva, P.H.N.; Guimarães, E.T. \& Lobo, D.J.A. 2001. Estudo anatômico foliar do clone híbrido 4430 de Tradescantia: alterações decorrentes da poluição aérea urbana. Revista Brasileira de Botânica 24: 567-576.

Bandulska, H. 1930. On the cuticules of recent and fossil Myrtaceae. Linneum Journal of Botany 48: 657-761.

Becana, M.; Dalton, D.A.; Moran, J.F.; Iturbe-Ormaetxe, I.; Matamoros, M. \& Rubio, M.C. 2000. Reactive oxygen species and antioxidants in leguna nodule. Physiologia Plantarum 109: 372-381.

Bennet, J.P.; Rassat, P.; Berrang, P. \& Karnosky, D.F. 1992. Relationships between leaf anatomy and ozone sensitivity of Fraxinus pennsylvanica Marsh. and Prunus serotina Ehrh. Environmental and Experimental Botany 32: 33-41.

Bray, E.A.; Bailey-Serres, J. \& Weretilnyk, E. 2000. Responses to abiotic stresses. Pp. 158-203. In: B.B. Bunchanan; W. Grussein \& R.L. Jones (eds.). Biochemistry \& Molecular Biology of Plants. New York, American Society of Plant Physiologists (USA).

CETESB. 2004. Relatório de qualidade do ar no Estado de São Paulo 2003. Série Relatórios.

Costa, C.G.; Machado, R.D. \& Fontenelle, J.B. 1995. Sistema vascular em folhas de Eugenia L. (Myrtaceae). Boletim do Herbarium Bradeanum 4: 345-355.

Domingos, M.; Alves, E.S.; Bulbovas, P.; Cunha, A.L.; Longui, E.L.; Lourençon, D.A.C.B.; Moraes, R.M.; Rinaldi, M.C.S. \& Viveiros, S.C.M. 2004. Reactions of Caesalpinia echinata Lam., a Brazilian tree species, to urban air pollution stress. Pp. 279-287. In: A. Klumpp; W. Ansel \& G. Klumpp (eds.). Urban Air Pollution, Bioindication and Environmental Awareness. Göttingen, Cuvillier Verlag.

Domingos, M.; Klumpp, A. \& Klumpp, G. 1998. Air pollution impact on the Atlantic forest in the Cubatão region, SP, Brazil. Ciência e Cultura 50: 230-236.

Eleftheriou, E.P. 1987. A comparative study of the leaf anatomy of olive trees growing in the city and the country. Environmental and Experimental Botany 27: 105-117.

Evans, L.S.; Albury, K. \& Jennings, N. 1996. Relationships between anatomical characteristics and ozone sensitivity of leaves of several herbaceous dicotyledonous plant species at Great Smoky Mountains National Park. Environmental and Experimental Botany 36: 413-420.

Falla, J.; Laval-Gilly, P.; Henryon, M.; Morlot, D. \& Ferard, J-F. 2000. Biological air quality monitoring: A review. Environmental Monitoring and Assessment 64: 627-644.

Ferdinand, J.A.; Fredericksen T.S.; Kouterick K.B. \& Skelly J. M. 2000. Leaf morphology and ozone sensitivity of two open pollinated genotypes of black cherry (Prunus serotina) seedlings. Environmental Pollution 108: 297-302. 
Fares, S.; Barta, C.; Brilli, F.; Centritto, M; Ederli, L.; Ferranti, F.; Pasqualini, S.; Reale, L.; Tricoli, D. \& Loreto, F. 2006. Impact of high ozone on isoprene emission, photosynthesis and hystology of developing Populus alba leaves directly or indirectly exposed to the pollutant. Physiologia Plantarum 128: 456-465.

Fernandes, A.J.; Reis, L.A.M. \& Carvalho, A. 2004. Caracterização do meio físico. Pp. 49-62. In: D.C. Bicudo; M.C. Forti \& C.E.M. Bicudo (orgs.). Parque Estadual das Fontes do Ipiranga (PEFI): unidade de conservação que resiste à urbanização de São Paulo. São Paulo, Secretaria do Meio Ambiente do Estado de São Paulo.

Ferri, M.G. 1971. Informações sobre transpiração e anatomia foliar de diversas Mirtáceas. Ciência e Cultura 23: 313-316.

Fink, S. 1991. Unusual patterns in the distribution on calcium oxalate in spruce needles in their possible relationships to the impact of pollutants. New Phytologist 119: 41-51.

Franceschi, V.R. \& Horner, H.T. 1980. Calcium oxalate crystals in plants. Botanical Review 46: 361-427.

Fontenelle, G.B.; Costa, C.G. \& Machado, R.D. 1994. Foliar anatomy and micromorphology of eleven species of Eugenia L. (Myrtaceae). Botanical Journal of the Linnean Society 115: 111-133.

Freedman, B. 1995. Environmental Ecology. $2^{\text {nd }}$ ed., San Diego, Academic Press Inc.

Furlan, C.M.; Santos, D.Y.A.C.; Salatino, A. \& Domingos, M. 2006. n-Alkane distribution of leaves of Psidium guajava exposed to industrial air pollutants. Environmental and Experimental Botany 58: 100-105.

Joly, A.B. 1977. Botânica: Introdução à Taxonomia Vegetal. 4 ed., São Paulo, Companhia Editora Nacional.

Klumpp, A.; Klumpp, G. \& Domingos, M. 1994. Plants as bioindicators of air pollution at the Serra do Mar near the industrial complex of Cubatão, Brazil. Environmental Pollution 85: 109-116.

Klumpp, A.; Domingos, M. \& Pignata, M.S. 2000. Air pollution and vegetation damage in South America state of knowledge and perspectives. Pp. 111-136. In: S.B. Agrawal \& M. Agrawal (eds.). Environmental pollution and plant responses. Boca Raton, London, New York, Washington, Lewis Publishers.

Kraus, J.E. \& Arduin, M. 1997. Manual básico de métodos em morfologia vegetal. Rio de Janeiro, Editora Universidade Rural.

Larcher, W. 2000. Ecofisiologia Vegetal. São Carlos, RiMa.

Machado, R.D.; Costa, C.G. \& Fontenelle, G.B. 1988. Anatomia foliar de Eugenia sulcata Spring ex Mart. (Myrtaceae). Acta Botanica Brasilica 1: 275-285.
Masuch, G.; Franz J.T.; Kicinski H.G. \& Kettrup, A. 1992. Histological and biochemical differences of alightly and severely injuried spruce needles of two stands in northrhine Westphalia. Environmental and Experimental Botany 32: 163-182.

Metcalf, C.R. \& Chalk, L. 1950. Anatomy of the Dicotyledons. Oxford, Clarendon Press.

Moraes, R.M.; Furlan, C.M.; Bulbovas, P.; Domingos, M.; Meirelles, S.T. \& Sanz, M.J. 2004. Photosynthetic responses of tropical trees to short-term exposure to ozone. Photosynthetica 42: 291-293.

Moraes, R.M.; Klumpp, A.; Furlan, C.M.; Klumpp, G.; Domingos, M.; Rinaldi, M.C.S. \& Modesto, I.F. 2002. Tropical fruit trees as bioindicators of industrial air pollution in southeast Brazil. Environment International 28: $367-374$

Päänkkönen, E.; Holopainen, T. \& Kärenlampi, L. 1995. Ageing - related anatomical and ultraestructural changes in leaves of Birch (Betula pendula Roth.) clones as affected by low ozone exposure. Anals of Botany 75: 285-294.

Päänkönen, E.; Holopainen, T. \& Kärenlampi, L. 1997. Differences in growth, leaf senescence and injury, and stomatal density in Birch (Betula pendula Roth.) in relation to ambient levels of ozone in Finland. Environmental Pollution 96: 117-127.

Pina, J.M. \& Moraes, R.M. 2007. Ozone-induced foliar injury in saplings of Psidium guajava 'Paluma'. Chemosphere 66: $1310-1314$.

Richter, H.G. 1981. Anatomia des sekundarem xylems under Rinde der Lauraceae. Sonderbande des Naturn. Verreins Hamburg 5. Hamburg, Paul Parey.

Sharma, G.K. \& Tyree, J. 1973. Geographic leaf cuticular and gross morphological variations in Liquidambar styraciflua $\mathrm{L}$. and their possible relationship to environmental pollution. Botanical Gazette 134: 179-184.

Silva, L.C.; Oliva, M.A.; Azevedo A.A.; Araújo, J.M. \& Aguiar, R.M. 2005. Micromorphological and anatomical alterations caused by simulated acid rain in restinga plants: Eugenia uniflora and Clusia hilariana. Water, Air and Soil Pollution 168: 129-143.

Souza, V.C. \& Lorenzi, H. 2005. Botânica Sistemática. Nova Odessa, Instituto Plantarum.

Van Wyk, A.E.; Robbertse, P.J. \& Rok, P.D.F. 1982. The genus Eugenia L. (Myrtaceae) in Southern Africa: the structure and taxonomic value of stomata. Journal of Linneum Society 84: 41-56. 